\title{
Effects of high altitude and cold air exposure on airway inflammation in patients with asthma
}

\author{
Sven F Seys, ${ }^{1,2}$ Marc Daenen, ${ }^{3}$ Ellen Dilissen, ${ }^{1}$ Ruud Van Thienen, ${ }^{4}$ \\ Dominique M A Bullens, ${ }^{5}$ Peter Hespel, ${ }^{4}$ Lieven J Dupont ${ }^{2,6}$
}

\begin{abstract}
- Additional material is published online only. To view please visit the journal online (http://dx.doi.org/10.1136/ thoraxjnl-2013-203280).

${ }^{1}$ Department of Immunology and Microbiology, Laboratory of Clinical Immunology, KU Leuven, Leuven, Belgium ${ }^{2}$ Department of Clinical and Experimental Medicine, Laboratory of Pneumology, KU Leuven, Leuven, Belgium ${ }^{3}$ Department of Respiratory Medicine, Hospital of OostLimburg, Leuven, Belgium

${ }^{4}$ Department of Kinesiology, Exercise Physiology Research Group, KU Leuven, Leuven, Belgium

${ }^{5}$ Department of Immunology and Microbiology, Laboratory of Pediatric Immunology, KU Leuven, Leuven, Belgium ${ }^{6}$ Department of Respiratory Diseases, University Hospitals Leuven, KU Leuven, Leuven, Belgium
\end{abstract}

\section{Correspondence to} Professor Lieven Dupont, Department of Respiratory Medicine, University Hospitals Leuven, KU Leuven, 49 Herestraat, Leuven B-3000, Belgium; lieven.dupont@uzleuven.be

Received 18 January 2013 Revised 7 May 2013 Accepted 30 May 2013 Published Online First 2 July 2013

\begin{tabular}{l}
\hline To cite: Seys SF, Daenen M, \\
Dilissen E, et al. Thorax \\
2013;68:906-913.
\end{tabular}

\section{ABSTRACT}

Aims Eighteen patients with asthma were evaluated during preparation to climb to extreme altitude in order to study the effects of low fractional inspired oxygen $\left(\mathrm{FiO}_{2}\right)$, prolonged exposure to cold air and high altitude on lung function, asthma control and airway inflammation.

Methods Spirometry and airway inflammation (fractional exhaled nitric oxide (FeNO) and induced sputum) were studied under different test conditions: hypoxic $\left(\mathrm{FiO}_{2}=11 \%\right)$ exercise test, 24-hour cold exposure $\left(-5^{\circ} \mathrm{C}\right)$ and before, during and after an expedition that involved climbing the Aconcagua mountain (6965 m).

Results Forced expiratory volume in $1 \mathrm{~s}\left(\mathrm{FEV}_{1}\right)$ and FeNO values were slightly lower $(p<0.04)$ after $1 \mathrm{~h}$ of normobaric hypoxia. FEV 1 decreased $(p=0.009)$ after 24-hour cold exposure, accompanied by increased sputum neutrophilia $(p<0.01)$. During the expedition $\mathrm{FEV}_{1}$ and forced vital capacity decreased (maximum FEV 1 decrease of $12.3 \%$ at $4300 \mathrm{~m}$ ) and asthma symptoms slightly increased. After the expedition the Asthma Control Test score and prebronchodilator $\mathrm{FEV}_{1}$ were reduced $(p<0.02)$, sputum neutrophil count was increased $(p=0.04)$ and sputum myeloperoxidase levels, sputum interleukin 17 mRNA, serum and sputum vascular endothelial growth factor $A$ levels were significantly higher compared with baseline. Patients with asthma with the lowest oxygen saturation during the hypoxic exercise test were more prone to develop acute mountain sickness.

Conclusions Exposure to environmental conditions at high altitude (hypoxia, exercise, cold) was associated with a moderate loss of asthma control, increased airway obstruction and neutrophilic airway inflammation. The cold temperature is probably the most important contributing factor as 24-hour cold exposure by itself induced similar effects.

\section{INTRODUCTION}

Asthma is a chronic inflammatory disease with reversible airway obstruction accompanied by chest tightness, dyspnoea and cough. ${ }^{1}$ However, most patients with asthma are able to deal with external physical triggers (eg, cold temperature or highintensity physical efforts) when their asthma is adequately controlled. ${ }^{2}$

Travelling to high altitude is assumed to be safe in patients with stable asthma ${ }^{2-4}$; decreases in peak flow rates may occur ${ }^{2}{ }^{3}$ but the incidence of acute mountain sickness (AMS) is not increased. ${ }^{4}$ Analysis of spirometry in a small group of subjects with asthma climbing to high altitude showed a

\section{Key messages}

\section{What is the key question?}

- Is it safe for patients with asthma to climb to extremen altitude and what is the effect on asthma symptoms, spirometry and airway inflammation?

\section{What is the bottom line?}

- Patients with well-controlled asthma are able to ascend to high altitude, but this induces increased symptoms and a neutrophilic inflammation which we were able to reproduce when patients were exposed for $24 \mathrm{~h}$ to cold air in normoxia.

\section{Why read on?}

- Cold air may damage airway epithelium and induce a neutrophilic type of inflammation different from the eosinophilic/Th2-driven inflammation that is classically seen in patients with asthma.

decrease in forced expiratory volume in $1 \mathrm{~s}\left(\mathrm{FEV}_{1}\right)$ and forced vital capacity (FVC) which were not significantly different from control subjects. ${ }^{5}$ Asthma symptom scores did not change, but $40 \%$ of the patients used more medication and $8 \%$ experienced a severe exacerbation. ${ }^{5}$

Asthma control at high altitude is affected by several environmental factors including allergen burden, cold air, hypoxia and air density. ${ }^{3}$ The decreased presence of allergens and lower air pollution at high altitude may explain the beneficial effect of high altitude training in subjects with asthma. ${ }^{6}$ Cold air is a known trigger for asthma, especially in combination with increased ventilation during exercise, ${ }^{78}$ which may explain the increased prevalence of asthma among cross-country skiers 89 and emphasises the need for optimal treatment in these athletes. ${ }^{8}$ Exposure to cold air at high altitude may thus counteract the beneficial effects of improved air quality.

In this study, 18 patients with asthma who participated in an expedition to climb the Aconcagua mountain $(6959 \mathrm{~m})$ were evaluated both during the 1-year preparation phase as well as during the actual ascent. This allowed us to study the effects of low fractional inspired oxygen $\left(\mathrm{FiO}_{2}\right)$, prolonged exposure to cold air and high altitude on lung function, asthma control and airway inflammation. 


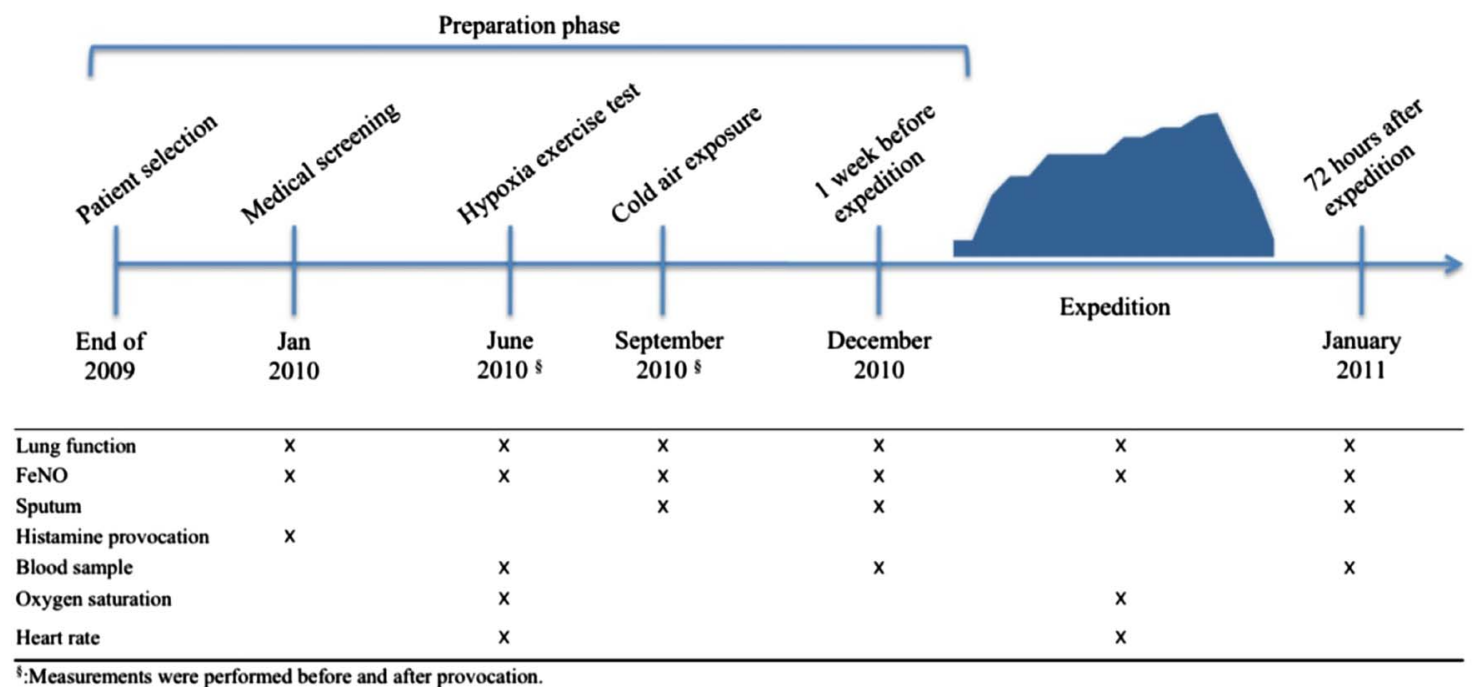

Figure 1 Schematic overview of the various times of evaluation during the preparation phase, expedition and $72 \mathrm{~h}$ after the expedition. During the expedition, measurements were performed at $750 \mathrm{~m}$ (Mendoza, $24^{\circ} \mathrm{C}$ ), $2600 \mathrm{~m}$ (Los Penitentes, $22^{\circ} \mathrm{C}$ ), $3400 \mathrm{~m}\left(\right.$ Confluenzia, $21^{\circ} \mathrm{C}$ ), $4300 \mathrm{~m}(\mathrm{Plaza}$ de Mulas, $\left.14^{\circ} \mathrm{C}\right), 5000 \mathrm{~m}\left(\right.$ Canada, $\left.4^{\circ} \mathrm{C}\right), 5600 \mathrm{~m}$ (Nido de Condores, $-2^{\circ} \mathrm{C}$ ) and $5963 \mathrm{~m}\left(\right.$ Colera, $\left.-12^{\circ} \mathrm{C}\right)$.

\section{METHODS}

A more detailed description of the methodology is available in the online supplement.

\section{Subjects}

Eighteen patients with asthma (13 men) were recruited to take part in an expedition to climb the Aconcagua mountain (6965 m) in Aconcagua National Park, Argentina.

\section{Study design}

Patients were evaluated at different time points during the year prior to the expedition as well as during the actual ascent (figure 1 and online supplement).

\section{Hypoxic exercise test}

A hypoxic exercise test was performed with exposure to normobaric $(760 \mathrm{~mm} \mathrm{Hg})$ hypoxia $\left(\mathrm{FiO}_{2} 11 \%\right)$. Patients were continuously monitored at rest for $30 \mathrm{~min}$ and during exercise (oxygen saturation, heart rate, ECG). Fractional exhaled nitric oxide (FeNO) measurement and spirometry were performed and venous blood samples were obtained before and after exposure to hypoxia.

\section{4-hour exposure to cold air}

Patients stayed for $24 \mathrm{~h}$ in an indoor ski area $\left(\leq-5^{\circ} \mathrm{C}\right)$. FeNO, spirometry and induced sputum were analysed before and immediately after the time spent in the indoor ski area and spirometry was also performed after $12 \mathrm{~h}$ in the indoor ski area.

\section{Expedition}

The altitude profile is shown in figure 1. Baseline measurements were carried out 5 days before departure and at the start of the expedition (spirometry, heart rate, blood pressure, oxygen saturation). All measurements were repeated $72 \mathrm{~h}$ after the ascent. During the expedition at the different altitudes, patients reported symptoms of AMS by means of the Lake Louise selfreport questionnaire. ${ }^{10}$ Peripheral oxygen saturation and heart rate were measured as well as daily asthma symptoms and use of asthma rescue medication. FeNO and spirometry were measured at different altitudes and compared with baseline levels. Partial pressure of nitric oxide in exhaled gas (PeNO) values were calculated as described previously. ${ }^{11}$

\section{Statistical analyses}

Statistical analyses were performed with Graphpad Prism V for Macintosh. Normality was analysed by the KolmogorovSmirnoff test and data were analysed by the paired Student $t$ test, the Wilcoxon signed ranked test, repeated measures ANOVA or the Friedman test where appropriate (Bonferroni's or Dunn's multiple comparison tests were used as a post test). Correlation was studied by the Spearman or Pearson test as appropriate.

\section{RESULTS}

\section{Baseline characteristics of patients}

The baseline characteristics of the patients are shown in table 1 . At screening, five patients had a prebronchodilator (pre-BD) $\mathrm{FEV}_{1}$ of $<80 \%$ predicted (table 1 ). Seventeen patients had wellcontrolled asthma (Asthma Control Test (ACT) $\geq 20 / 25$ ). Ten patients had a FeNO value of $>25 \mathrm{ppb}$, indicating that these patients possibly had more airway inflammation. In these patients the inhaled steroid dose was increased after the first visit. Subsequent treatment was kept unchanged in all subjects during the preparation. Mean pre-BD $\mathrm{FEV}_{1} \%$ predicted (January: 91.8\% $21.5 \%$, December: $90.2 \% \pm 12.1 \%$ ) and ACT

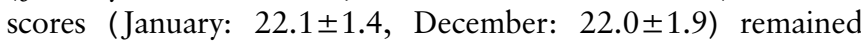
unchanged when evaluated at the end of the preparation period prior to the expedition. Median FeNO levels decreased during the year (January: $27.8 \mathrm{ppb}$ (IQR 17.2-35.3), June: $19.0 \mathrm{ppb}$ (IQR 12.3-27.6) and December: $18.1 \mathrm{ppb}$ (IQR 14.4-24.3), $\mathrm{p}=0.009$ ) and only four patients had FeNO values $>25 \mathrm{ppb}$ at the end of the year of preparation compared with 10 patients at screening.

\section{Hypoxic exercise test}

Oxygen saturation decreased (mean oxygen saturation at $30 \mathrm{~min}$ $79.3 \% \pm 8.7 \% ; \mathrm{p}<0.0001$ ) and heart rate increased (mean heart rate at $30 \mathrm{~min} 80.4 \pm 15.1 \mathrm{bpm} ; \mathrm{p}=0.004)$ significantly after $30 \mathrm{~min}$ at rest in the hypoxic chamber (figure $2 \mathrm{~A}, \mathrm{~B}$ ). A further decrease in oxygen saturation and increase in heart rate was seen during exercise (figure $2 \mathrm{~A}, \mathrm{~B}$ ). $\mathrm{FEV}_{1} \%$ predicted did not 
Table 1 Subject characteristics

\begin{tabular}{|c|c|c|c|}
\hline & Baseline & Before expedition & After expedition \\
\hline Subjects (M/F) & $13 / 5$ & & \\
\hline Age (years) & $39.6 \pm 11.3$ & & \\
\hline Inhaled steroids, n (\%) & $13(72 \%)$ & $16(89 \%)$ & \\
\hline High dose & $2(11 \%)$ & $3(17 \%)$ & \\
\hline Medium dose & $3(17 \%)$ & $8(44 \%)$ & \\
\hline Low dose & $8(44 \%)$ & $5(28 \%)$ & \\
\hline LABA, n (\%) & $12(67 \%)$ & $15(83 \%)$ & \\
\hline SABA alone, $n$ (\%) & $5(28 \%)$ & $2(11 \%)$ & \\
\hline LTRA, n (\%) & $6(33 \%)$ & $5(28 \%)$ & \\
\hline Pre-BD FEV 1 ( $\%$ pred $)$ & $92.0 \pm 21.5$ & $90.2 \pm 12.0$ & $83.6 \pm 10.3 \dagger$ \\
\hline Pre-BD FVC (\% pred) & $116.0 \pm 14.4$ & $116.8 \pm 14.4$ & $102.7 \pm 15.9+\dagger$ \\
\hline $\mathrm{FEV}_{1} / \mathrm{FVC}(\%)$ & $66.0 \pm 14.5$ & $66.0 \pm 12.0$ & $69.5 \pm 9.5$ \\
\hline FeNO (ppb) & $17.2-27.8-35.3$ & 14.4-18.1-24.3‡ & $8.0-13.5-23.8$ \\
\hline $\mathrm{ACT}$ & $22.0 \pm 1.4$ & $22.0-1.9$ & $18.2 \pm 4.3$ \\
\hline History of allergy & $18(100 \%)$ & & \\
\hline Total IgE (kU/L) & $45.2-93.1-228.3$ & & \\
\hline \multicolumn{4}{|l|}{ Sputum analysis } \\
\hline Total cell count $\left(\times 10^{6} / \mathrm{mL}\right)$ & $0.4-0.8-1.4$ & $0.6-0.9-1.9$ & $1.0-1.7-1.8$ \\
\hline Eosinophils (\%) & $0.0-2.0-6.3$ & $0.0-0.0-0.0 \S$ & $0.0-0.0-0.0^{*}$ \\
\hline Neutrophils (\%) & $2.3-9.5-20.8$ & $16.8-30.5-51.8$ & $40.0-51.0-74.0^{* *}$ \\
\hline Macrophages (\%) & $77.0-87.0-95.8$ & $44.0-64.0-85.0$ & $26.0-45.0-54.0^{* *}$ \\
\hline Lymphocytes (\%) & $0.0-0.0-1.0$ & $0.0-1.0-8.0$ & $2.0-5.0-7.0^{* *}$ \\
\hline
\end{tabular}

change $(p=0.48)$ after $30 \mathrm{~min}$ at rest in hypoxia $\left(\mathrm{FiO}_{2} 11 \%\right)$ and decreased after maximal exercise in hypoxia (mean change $2 \%$ (95\% CI $-0.3 \%$ to $4.3 \%$ ), $\mathrm{p}=0.04$; table 2). Median FeNO values were slightly but significantly lower after maximal exercise in hypoxia compared with baseline (17.5 ppb vs $19.0 \mathrm{ppb}$, $\mathrm{p}=0.03$; table 2). None of the patients reported an increase in asthma symptoms. Complement factor $3(\mathrm{p}<0.0001$; table 2$)$, $\alpha_{1}$-antitrypsin $(p<0.0001$; table 2$)$ and high-sensitive $C$ reactive protein $(p=0.047$; table 2$)$ increased significantly after maximal

Table 2 Hypoxic exercise test

\begin{tabular}{llllc}
\hline & Baseline & After 30 min & After exercise & p Value \\
\hline FEV $_{1}(\%$ pred) & $100.3 \pm 15.3$ & $104.2 \pm 15.3 \dagger$ & $99.7 \pm 15.0 \dagger \dagger$ & 0.05 \\
FeNO (ppb) & $13.0-19.0-27.3$ & & $11.1-17.5-22.0$ & 0.03 \\
$\alpha_{1}-$ AT & $1.2-1.3-1.5$ & & $1.3-1.4-1.6$ & $<0.0001$ \\
C3 & $0.9-1.0-1.2$ & & $1.0-1.0-1.3$ & $<0.0001$ \\
hs-CRP & $0.4-0.5-1.4$ & & $0.5-0.7-1.4$ & 0.047
\end{tabular}

$\mathrm{FEV}_{1} \%$ predicted was measured at baseline, after $30 \mathrm{~min}$ at rest and after a maximal incremental exercise protocol under hypoxic conditions (fractional inspired oxygen $11 \%$ ). FeNO, serum $\alpha_{1}-A T$, serum C3 and serum hs-CRP were measured at baseline and after exercise.

Patients $(n=17)$ were asked to run on a treadmill starting at $6 \mathrm{~km} / \mathrm{h}$ for $10 \mathrm{~min}$ followed by an increase of $1 \mathrm{~km} / \mathrm{h}$ each $3 \mathrm{~min}$ until exhaustion. Paired t test (FEV ${ }_{1} \%$ predicted, $\alpha_{1}$-AT and C 3 ) or Wilcoxon signed rank test (FeNO and hs-CRP) were used to compare paired data before and after the test.

$\mathrm{p}$ Values represent comparison of measurements after exercise compared with baseline: $t p=0.48 ;+t p=0.04$.

$\alpha_{1}$-AT, $\alpha_{1}$-antitrypsin; C3, complement factor 3 ; FeNO, fractional exhaled nitric oxide;

$\mathrm{FEV}_{1}$, forced expiratory volume in $1 \mathrm{~s}$; hs-CRP, high sensitive-C reactive protein. exercise in hypoxia compared with baseline measurements in normoxia.

\section{Cold exposure test}

$\mathrm{FEV}_{1} \%$ predicted decreased significantly after 12 and $24 \mathrm{~h}$ of cold air exposure compared with baseline measurements (mean change in $\mathrm{FEV}_{1}$ after $12 \mathrm{~h} 11.9 \%$ (95\% CI $6.8 \%$ to $17.1 \%$ ), $\mathrm{p}<0.0001$; mean change in $\mathrm{FEV}_{1}$ after $24 \mathrm{~h} 5.5 \%$ (95\% CI $0.2 \%$ to $10.9 \%), p \leq 0.02$; figure $3 \mathrm{~A})$. FeNO values did not change significantly (figure $3 \mathrm{~B}$ ). Total cell count in sputum significantly increased (mean change $737 \times 10^{3}$ cells $(95 \%$ CI $1198 \times 10^{3}$ to $\left.277 \times 10^{3}\right), p=0.002$; data not shown). Median sputum neutrophil percentages were also significantly higher after $24 \mathrm{~h}$ of cold air exposure than at baseline (55\% vs $9.5 \%$, $\mathrm{p}=0.01$; figure 3C). Sputum interleukin (IL)-17A $(\mathrm{p}=0.001)$ and IL-5 $(p=0.002)$ mRNA levels increased significantly and sputum IL-4 $(p=0.001)$ mRNA levels decreased significantly after cold exposure (figure 3D). Eight patients reported an increase in asthma symptoms during cold exposure which necessitated additional bronchodilator treatment with salbutamol in five cases.

\section{Expedition}

A decline in oxygen saturation and an increase in heart rate were observed after each increase of altitude followed by recovery during subsequent days at the same altitude, suggestive of an acclimatisation effect (figure 4A,B). A significant decline in spirometry values was observed during the expedition; the maximal decrease in $\mathrm{FEV}_{1}$ and FVC of $-12.3 \%$ and $-18.9 \%$, 

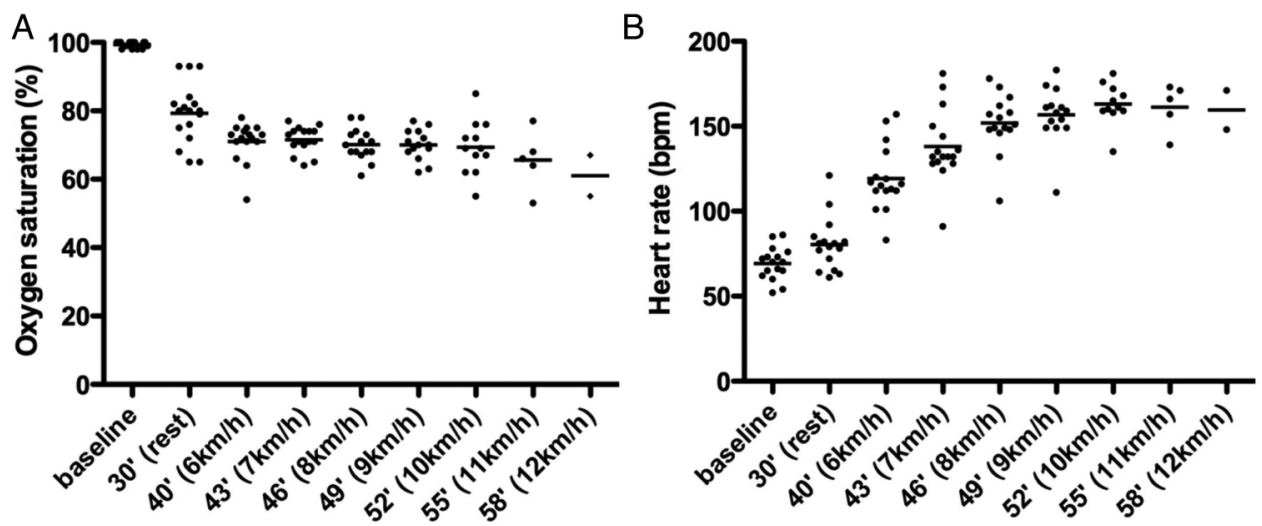

Figure 2 Hypoxic exercise test. (A) Oxygen saturation and (B) heart rate during 30 min at rest followed by a maximal incremental exercise protocol under hypoxic conditions (fractional inspired oxygen 11\%). Patients $(n=17)$ were asked to run on a treadmill starting at $6 \mathrm{~km} / \mathrm{h}$ for $10 \mathrm{~min}$ followed by an increase of $1 \mathrm{~km} / \mathrm{h}$ each $3 \mathrm{~min}$ until exhaustion. Data are represented as dots with mean values.

respectively, occurred at $4300 \mathrm{~m}$ and did not appear to decrease further at higher altitude $\left(\mathrm{FEV}_{1}\right.$ and $\mathrm{FVC} 98.2 \%$ and $94.1 \%$ of baseline, respectively at $5600 \mathrm{~m}$; figure 4A,C,D).

The pre-BD $\mathrm{FEV}_{1} \%$ predicted was significantly lower when evaluated $72 \mathrm{~h}$ after the expedition compared with the measurement before the expedition (mean change 6.6\% (95\% CI 2.0\% to $11.2 \%), p=0.004$; table 1 ). A decrease of more than $10 \%$ was observed in four of the 18 patients with asthma. During the expedition there was a small but significant increase in the daily asthma symptom score (from 0.2 at $750 \mathrm{~m}$ to 0.8 at $6000 \mathrm{~m}$; $\mathrm{p}=0.0124)$. One patient who experienced a severe exacerbation at $4300 \mathrm{~m}$ was treated with oral steroids and did not climb to higher altitude. There was an increase in the use of asthma rescue medication at $5600 \mathrm{~m}$ and $6000 \mathrm{~m}$. The mean ACT score was significantly lower when assessed after the expedition $(\mathrm{ACT}=18 / 25 ; \mathrm{p}=0.002)$.

PeNO values did not change significantly during the expedition except for a small drop in the PeNO value at $5600 \mathrm{~m}$ (figure 4E). Sputum neutrophil percentages (mean change $15.2 \%$ (95\% CI $-3.4 \%$ to $33.8 \%$ ), $\mathrm{p}=0.049$; figure $5 \mathrm{~A}$ ) and median myeloperoxidase levels (23.1 vs $102.0 \mathrm{ng} / \mathrm{ml}, \mathrm{p}=0.002$; data not shown) increased significantly after the expedition accompanied by an increase in sputum IL-17A mRNA $(\mathrm{p}=0.007$; figure 5B). Sputum IL-5 mRNA levels also increased
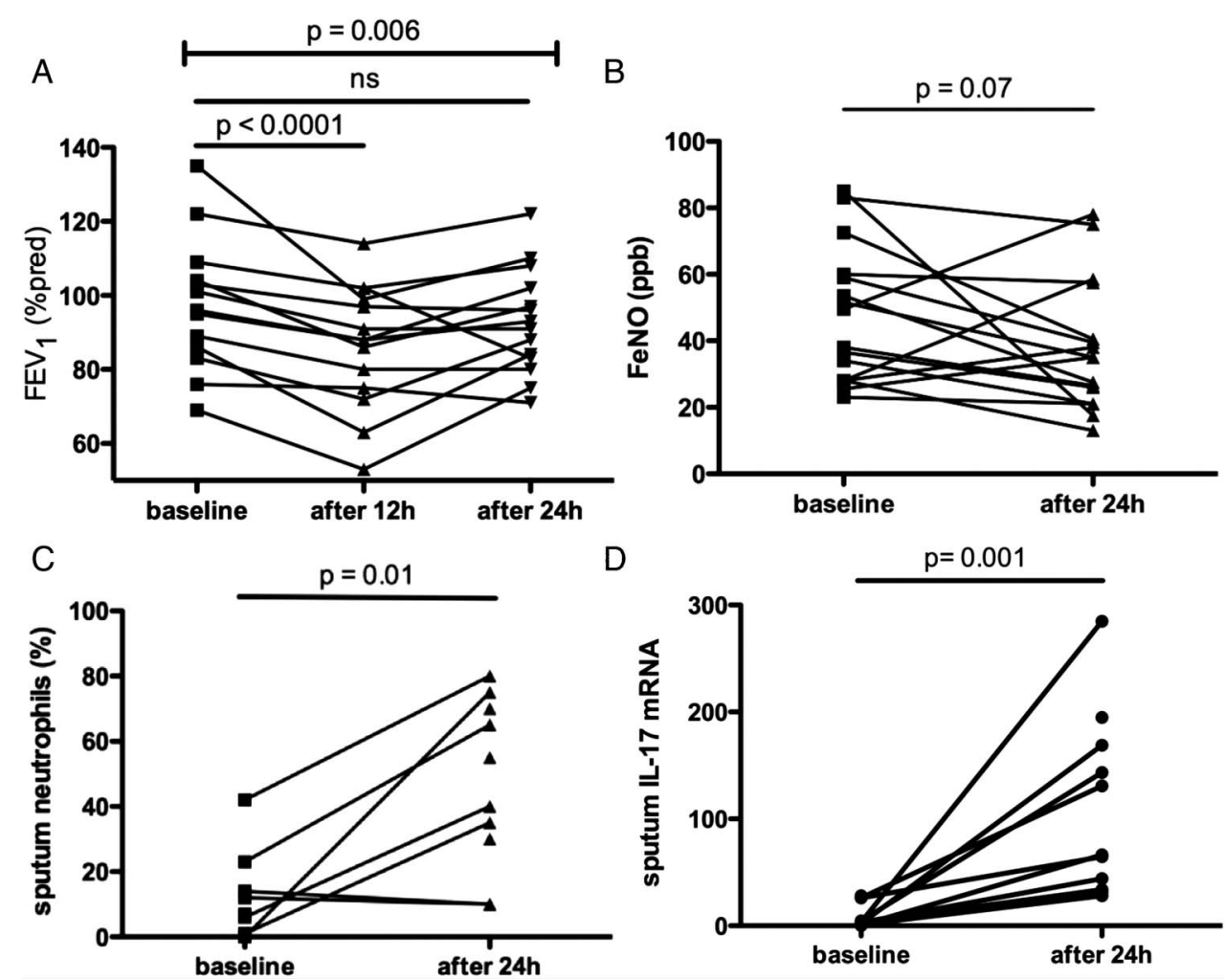

Figure 3 Cold exposure test. $(A)$ Forced expiratory volume in $1 \mathrm{~s}\left(\mathrm{FEV}_{1}\right)$ was measured by spirometry $(\mathrm{n}=16)$ at baseline, after $12 \mathrm{~h}($ at the indoor ski run) and after $24 \mathrm{~h}$. (B) Fractional expired nitric oxide (FeNO) levels and induced sputum (percentage neutrophils (C), interleukin (IL)-17A mRNA (D)) were obtained at baseline and after $24 \mathrm{~h}$. Repeated measures ANOVA (with Bonferroni's multiple comparison test as a post test) (A), paired $t$ test $(B, C)$ or Wilcoxon signed rank test $(D)$ were used to analyse the results. 


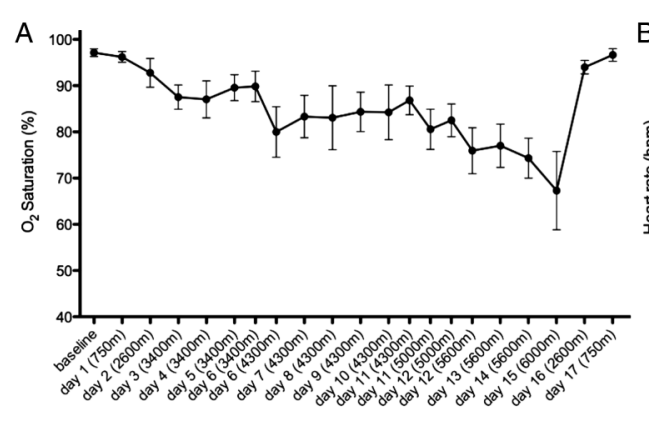

D

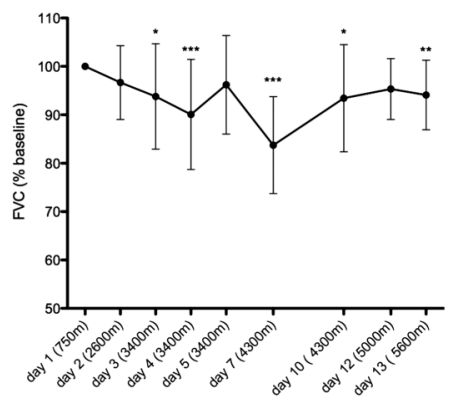

E
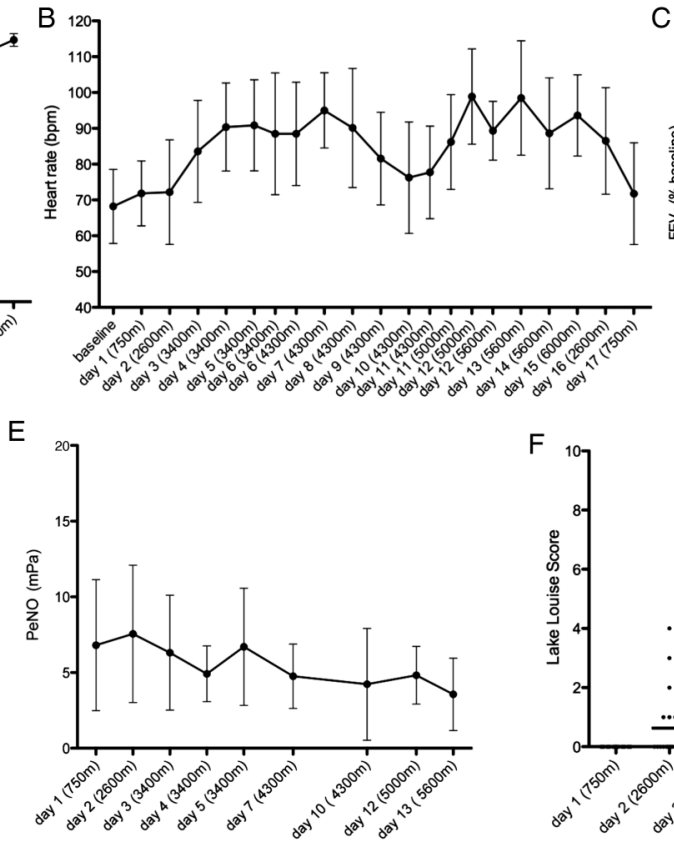

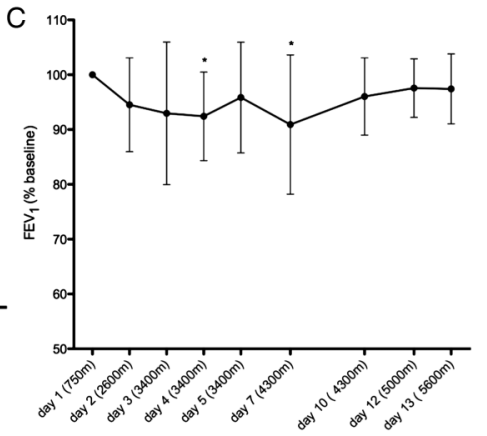

$\mathrm{F}$

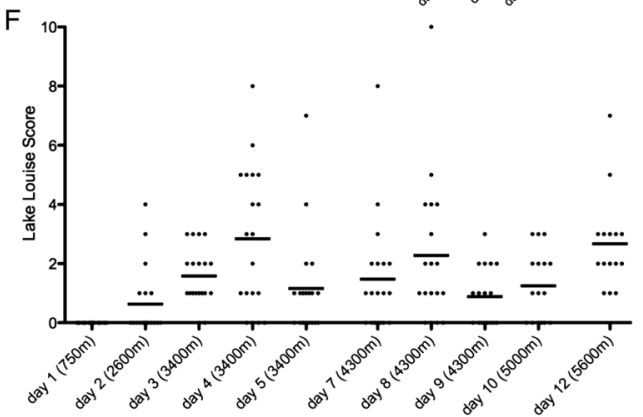

Figure 4 Clinical parameters during expedition. (A) Oxygen saturation, (B) heart rate, (C) forced expiratory volume in $1 \mathrm{~s}(\mathrm{FEV})_{1} \%$ at baseline, (D) forced vital capacity (FVC)\% at baseline and (E) partial pressure of nitric oxide in exhaled gas (PeNO) were measured regularly at different altitudes during the expedition. Data are represented as mean values with SD (A-E). (F) Individual and mean values of Lake Louis score are represented by dots and as a horizontal bar, respectively. Data were analysed by Dunn's multiple comparison test: ${ }^{*} p<0.01$; ${ }^{* *} p<0.001$; ${ }^{* *} p<0.0001$.

after the expedition but no difference was found for IL-4 and interferon $\gamma$ mRNA levels $(p=0.52$ and $p=0.086$, respectively; figure $5 \mathrm{C})$ and sputum eosinophil count $(\mathrm{p}=0.50$; data not shown). We could not detect higher levels of serum Clara Cell 16 (CC16) protein, a marker for epithelial damage, ${ }^{12}$ after the expedition compared with baseline measurements $(p=0.36$; data not shown), but there was a positive correlation between sputum IL-17A mRNA and serum CC16 protein (Spearman $\mathrm{r}=0.57, \mathrm{p}=0.008$; data not shown). Both serum and sputum vascular endothelial growth factor A (VEGF-A) levels were significantly increased after the expedition compared with baseline measurements (serum protein levels: $57.3 \mathrm{pg} / \mathrm{mL}$ (95\% CI 14.2 to 100.3 ), $\mathrm{p}=0.02$; figure $5 \mathrm{D}$; mean change in sputum mRNA levels: 2.5 copies (95\% CI 0.2 to 4.7$), \mathrm{p}=0.018$; figure $5 \mathrm{E}$ ).

There was an increase in the Lake Louise score (LLS) with increasing altitude (figure 4F). Symptoms increased on the first day at $3400 \mathrm{~m}$ and $4300 \mathrm{~m}$ and tended to decrease on the following days at the same altitude. Three patients experienced severe symptoms of AMS (LLS > 5) which prevented them from climbing to higher altitude. These three patients all had an oxygen saturation of $\leq 60 \%$ during the hypoxic exercise test, while only 2 of the 15 patients with asthma who did not develop severe AMS had an oxygen saturation of $\leq 60 \%$ during the hypoxic exercise test (Fisher exact test, $\mathrm{p}=0.01$ ). The minimal oxygen saturation during the hypoxic exercise test in the preparation period correlated positively with the maximal LLS score during the expedition (Pearson $r=-0.68, p=0.0009$; figure 6).

\section{DISCUSSION}

In this study we evaluated a small group of patients with asthma during an expedition to extreme altitude as well as during the preparation phase. The main findings of our study were: (1) patients with asthma with adequate asthma control are able to climb to high altitude (>4000 m); (2) exposure to environmental conditions at high altitude (hypoxia, exercise, cold) was associated with a moderate loss of asthma control and neutrophilic airway inflammation; (3) the cold temperature probably features as the most important contributing factor, as 24-hour exposure to cold by itself induced increased airway obstruction and increased airway neutrophilia; (4) climbing to altitudes $>4000 \mathrm{~m}$ was associated with a small restrictive impairment of dynamic lung volumes and $17 \%$ of the patients with asthma experienced severe AMS; (5) asthma patients with the lowest oxygen saturation at the end of a maximal exercise test during hypoxia were more prone to develop AMS during the expedition.

In our study we found a loss of asthma control after the expedition at high altitude that was associated with increased asthma symptoms and rescue medication use as well as a reduction in pre-BD FEV ${ }_{1}$. Nevertheless, most of the patients with asthma were able to climb to high altitude $(>5000 \mathrm{~m})$ and only one patient experienced a severe asthma exacerbation. As a result, we feel that climbing to high altitude should not be considered as a contraindication for patients with asthma who are well-controlled and who take appropriate preparatory measures. This agrees with previous data in the literature, although limited information was available about the exposure of subjects with asthma to high altitude and the suitability of mountaineering as an appropriate form of sport for them. In a study by Golan et al, ${ }^{13} 147$ patients with asthma were identified who had engaged in high altitude trekking. Two independent risk factors for attacks during travel were identified: frequent use ( $>3$ times weekly) of inhaled bronchodilators before travel and participation in intensive physical exertion during treks. Cogo et $a l^{14}$ studied the effect of high altitude on bronchial hyperresponsiveness both at Capanna Regina Margherita (4559 m) and Pyramid Laboratory in the Himalayas $(5050 \mathrm{~m})$ in a group of 11 patients with mild asthma in a stable condition and with normal respiratory function at sea level. None of the patients participating in these studies experienced a severe asthma exacerbation. A significant reduction of bronchial responsiveness to both challenges 

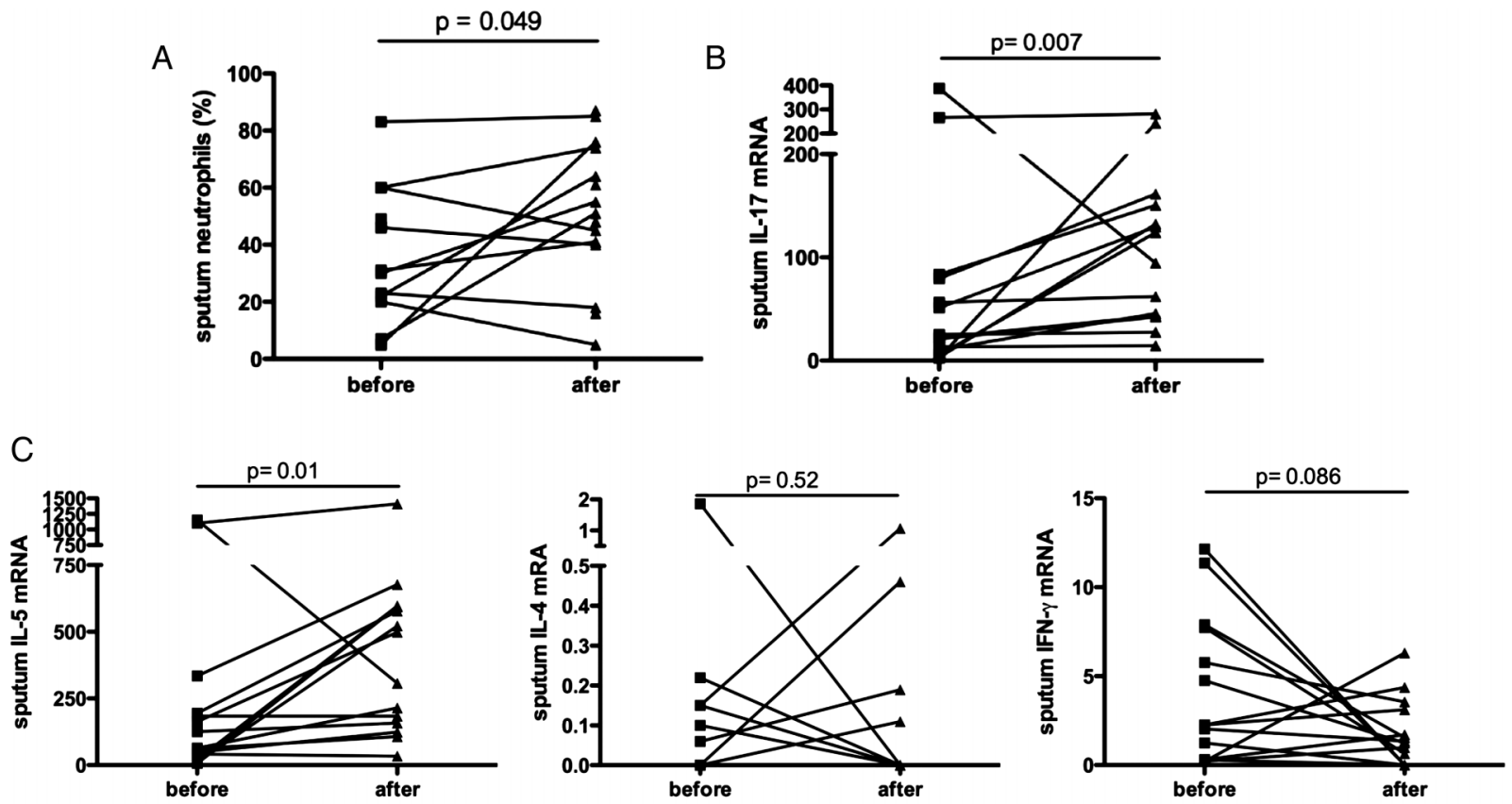

D
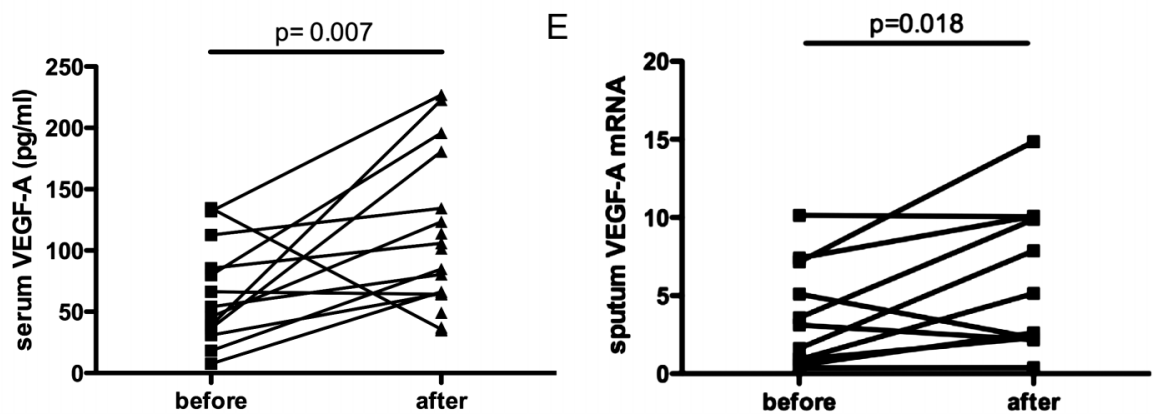

Figure 5 Airway inflammation before and after the expedition. Induced sputum cells (\% neutrophils, A) and peripheral blood were obtained before and after return from the expedition. Sputum interleukin (IL)-17A (B), IL-4, IL-5, interferon (IFN)- $\gamma$ (C) and vascular endothelial growth factor A (VEGF-A) (E) mRNA was quantified by real-time PCR and normalised to $\beta$-actin. Serum VEGF-A (D) protein levels were measured by ELISA. Data were analysed by paired t test $(A, D-E)$ or Wilcoxon signed rank test $(B-C)$ where appropriate.

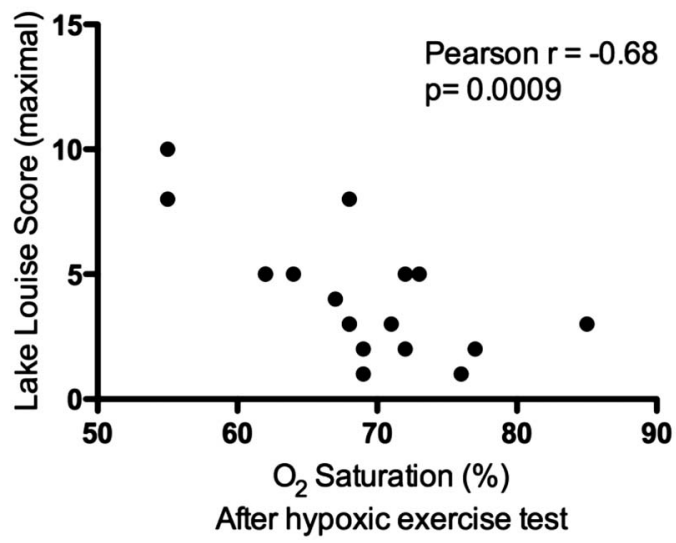

Figure 6 Inverse relation between lowest oxygen saturation after hypoxic exercise test and maximal Lake Louis score during the expedition. Oxygen saturation was continuously measured during $30 \mathrm{~min}$ at rest followed by a maximal incremental exercise protocol under hypoxic conditions (fractional inspired oxygen 11\%). The Lake Louis score was measured daily during the expedition to assess acute mountain sickness. The Pearson test was used to evaluate the association between the two parameters. was demonstrated at the highest altitude. ${ }^{14} 15$ Huismans et al evaluated 24 patients with asthma during trekking at high altitude in the Tibetan Everest region. ${ }^{5}$ Asthma symptoms did not significantly increase during the expedition. Similar to our data, two of the 24 subjects in this study experienced a severe asthma exacerbation and $40 \%$ had increased medication use. There may be a number of reasons for the relatively low incidence of acute asthma exacerbations in our study and previous studies. The patients with asthma who participated were selected on the basis of adequate asthma control and asthma medication was optimised several months prior to the expedition. Allergen avoidance at higher altitude with subsequent improvement of bronchial responsiveness and airway inflammation may also result in a favourable effect on asthma symptoms. ${ }^{6} 1617$ A few studies documented higher levels of catecholamines and corticosteroids during the first 2 weeks of altitude exposure. ${ }^{18} 19$ Increased plasma epinephrine and steroid concentrations, in addition to the anti-inflammatory treatment, can also reduce hyperresponsiveness and subsequent symptoms in subjects with asthma. ${ }^{20-22}$

Despite the fairly moderate increase in asthma symptoms and medication use as well as a limited reduction in pre-BD $\mathrm{FEV}_{1}$, we have shown that the expedition resulted in increased airway 
inflammation with a predominant neutrophilic infiltration into the airways. PeNO values were measured during the expedition and tended to decrease slightly. Similarly, sputum eosinophils evaluated after the expedition did not increase significantly. However, the absolute and relative number of neutrophils in sputum significantly increased, which is an important observation in our study. There are no previous studies evaluating airway inflammation in subjects with asthma or normal subjects when exposed to high altitude. We hypothesise that the combination of cold air (lowest temperature measured inside tent during the expedition was $-16^{\circ} \mathrm{C}$ ) and high ventilation rate may feature as the most important contributing factor in provoking airway obstruction and inflammation, as we showed in these patients with asthma that short-term exposure to cold air $(24 \mathrm{~h}$ at $\leq-5^{\circ} \mathrm{C}$ in normoxia) prior to the expedition by itself also induced airway obstruction with a significant increase in sputum neutrophils without affecting FeNO levels. These findings are in agreement with studies evaluating airway inflammation in athletes with asthma performing sports that require high ventilation targets in cold circumstances. ${ }^{23}$ Athletes exposed to cold air have a higher prevalence of asthma and airway hyperreactivity ${ }^{24}$ and also have a higher density of neutrophils in bronchial biopsy specimens. ${ }^{25}$ Athletes exposed to cold air also have slightly more bronchial epithelial cells in the airways compared with healthy subjects and their sputum neutrophil count correlated positively with the duration of training. ${ }^{26}$ This suggests that cold air-whether or not combined with exercise-may negatively affect lung function and induce a neutrophilic type of inflammation different from the eosinophilic/Th2-driven inflammation that is classically seen in patients with asthma. IL-17A is thought to be responsible for attracting neutrophils to the site of inflammation via induction of IL-8 in airway structural cells. ${ }^{27}$ The source of IL-17A in the airways of patients with asthma is a matter of debate. In patients with newly diagnosed cystic fibrosis, CD4 T lymphocytes express IL-17A in the airway wall. ${ }^{28}$ Neutrophils themselves may produce IL-17A in patients with cystic fibrosis and thereby contribute to a positive feedback loop. ${ }^{28} 29$ A high ventilation rate or long-term exposure to cold air may directly damage the airway epithelium and activate the immune system. Serum CC16 levels were measured to evaluate airway epithelium damage, but no difference was detected when evaluated after the expedition. Increased serum CC16 levels might, however, be a measure of acute damage and therefore no longer elevated $72 \mathrm{~h}$ after the expedition. On the other hand, a positive correlation was found between sputum IL-17 mRNA levels and serum CC16 levels, indicating a possible relation between airway epithelium damage and activation of the IL-17A/neutrophil axis. Our small study population did not allow us to analyse the impact of cold exposure on different asthma endotypes or phenotypes, but it could be speculated that patients with asthma with a neutrophilic endotype might be more prone to develop increased neutrophilic airway inflammation when climbing to high altitude or exposure to cold.

In addition to cold air, the subjects with asthma were exposed to hypoxia during the expedition. As a result, oxygen saturation progressively decreased and heart rate at rest increased. It is known that VEGF-A is induced by hypoxia. ${ }^{30}$ We found that both sputum VEGF-A mRNA and serum VEGF-A protein levels were significantly increased after the expedition. VEGF-A may increase vascular permeability and, by doing so, could facilitate transient migration of inflammatory cells to the interstitium and airway lumen. VEGF-A recruits a proangiogenic subset of neutrophils in transplanted hypoxic tissue. ${ }^{31}$ Placental growth factor, another member of the VEGF family, was shown to induce IL-17A and recruiting neutrophils to the airways in an asthma mouse model. ${ }^{32}$ Our results corroborate the previous data that VEGF-A may contribute to increased airway neutrophils after exposure to prolonged hypoxia.

A reduction in both $\mathrm{FEV}_{1}$ and $\mathrm{FVC}$ was shown in our study during the expedition, which was partially reversible after acclimatisation. This restrictive impairment corroborates previous data showing a reduction in dynamic lung volumes in both normal subjects studied in real and simulated altitude and in subjects with asthma. ${ }^{5} 1516$ Huismans et al observed similar changes in lung function in both patients with asthma and normal subjects with increasing altitude. Several factors may explain the observed decline in lung function such as occurrence of (subclinical) pulmonary oedema, increased central blood volume, reduced respiratory muscle force or a combination of these factors. ${ }^{3}$ Several of our subjects with asthma experienced minor and transient symptoms of AMS (LLS $<5)$, but only a few developed severe AMS (LLS > 5) which prevented them from climbing to higher altitude. The patients with asthma who experienced severe AMS during our expedition also seemed to have the lowest peripheral oxygen saturation during the preliminary hypoxic exercise test. These findings are in agreement with previous studies that found a correlation between low arterial oxygen saturation and the incidence of AMS. ${ }^{33} 34$ Karinen $e t a l^{34}$ also showed that climbers who had high arterial oxygen saturation at rest and after exercise at high altitude were less prone to develop AMS. The pathophysiology of AMS is not exactly known, although hypoventilation, impaired gas exchange, increased sympathetic activity, fluid retention and redistribution and raised intracranial pressure are likely to be involved. ${ }^{35}$ Hypoxaemia increases the blood flow by vasodilation and, together with an altered permeability of the bloodbrain barrier, predisposes to cerebral oedema. Performing a hypoxic exercise test may be helpful in trying to identify those individuals with asthma who are most likely to develop AMS.

\section{Conclusions}

Patients with asthma can travel to high altitude when their asthma is well-controlled. Close follow-up is advised because loss of asthma control may occur, the exposure to cold temperatures could promote a neutrophilic airway inflammation and some patients may experience an acute exacerbation. A hypoxic exercise test may identify those patients with asthma who are likely to suffer from AMS when climbing to high altitude.

Acknowledgements Our special thanks go to Sofie Bradt and Kris Peeters (Government of Flanders), to Kristof De Smet, Bert Ackaert and Paul Van Den Bosch (Energy Lab), to Katia Stroobants, Christophe Impens and Bob Verbeeck (Golazo), to Manuel Bustelo and Ulises Corvalán (Fernando Grajales Expeditions) and to the patients who were crucial in making this project possible.

Funding The study was funded by the Interuniversity Attraction Pole (IUAP, P6/35), Belgium and the Asthma Aconcagua Project. LJD and DMAB are recipients of a senior researcher fellowship from the Fund for Scientific Research Flanders (FWO).

Contributors SFS, ED, RVT, MD and LJD performed the experiments. SFS, PH, $D M A B$ and LJD were responsible for the study design, analysed the data and wrote the paper.

\section{Competing interests None.}

Ethics approval Ethics approval was obtained from the Institutional Review Board, University Hospital Leuven, Belgium.

Provenance and peer review Not commissioned; externally peer reviewed.

\section{REFERENCES}

1 Busse WW, Lemanske RF. Asthma. N Engl J Med 2001;344:350-62.

2 Louie D, Paré P. Physiological changes at altitude in nonasthmatic and asthmatic subjects. Can Respir J 2004;11:197-9. 
3 Luks AM, Swenson ER. Travel to high altitude with pre-existing lung disease. Eur Respir I 2007;29:770-92.

4 Stokes S, Kalson N, Earl M, et al. Bronchial asthma on Mount Kilimanjaro is not a disadvantage. Thorax 2008;63:936-7.

5 Huismans HK, Douma WR, Kerstjens HAM, et al. Asthma in patients climbing to high and extreme altitudes in the Tibetan Everest region. J Asthma 2010;47:614-19.

6 Rijssenbeek-Nouwens LH, Fieten KB, Bron AO, et al. High-altitude treatment in atopic and nonatopic patients with severe asthma. Eur Respir J 2012;40:1374-80.

7 Parsons JP, Mastronarde JG. Exercise-induced asthma. Curr Opin Pulm Med 2009:15:25-8.

8 Carlsen K-H. Sports in extreme conditions: the impact of exercise in cold temperatures on asthma and bronchial hyper-responsiveness in athletes. $\mathrm{Br} J \mathrm{Sports}$ Med 2012:46:796-9.

9 Larsson $\mathrm{K}$, Ohlsen $\mathrm{P}$, Larsson $\mathrm{L}$, et al. High prevalence of asthma in cross country skiers. BMJ 1993;307:1326-9.

10 Hackett PH, Oelz O. The Lake Louise consensus on the definition and qualification of altitude illness. In: Sutton J, Coates G, Houston C, eds. Hypoxia mountain medicine. Burlington, Vermont: Queen City Printers, 1992:327-30.

11 Caspersen C, Stang J, Thorsen E, et al. Exhaled nitric oxide concentration upon acute exposure to moderate altitude. Scand I Med Sci Sports 2013;23:e102-7

12 Broeckaert, Bernard. Clara cell secretory protein (CC16): characteristics and perspectives as lung peripheral biomarker. Clin Exp Allergy 2000;30:469-75.

13 Golan Y, Onn A, Villa Y, et al. Asthma in adventure travelers: a prospective study evaluating the occurrence and risk factors for acute exacerbations. Arch Intern Med 2002:162:2421-6.

14 Cogo A, Basnyat B, Legnani D, et al. Bronchial asthma and airway hyperresponsiveness at high altitude. Respiration 1997;64:444-9.

15 Allegra L, Cogo A, Legnani $D$, et al. High altitude exposure reduces bronchia responsiveness to hypo-osmolar aerosol in lowland asthmatics. Eur Respir J 1995:8:1842-6.

16 Pollard AJ, Mason NP, Barry PW, et al. Effect of altitude on spirometric parameters and the performance of peak flow meters. Thorax 1996:51:175-8.

17 Fischer R, Lang SM, Bergner A, et al. Monitoring of expiratory flow rates and lung volumes during a high altitude expedition. Eur J Med Res 2005;10:469-74.

18 Cunningham WL, Becker EJ, Kreuzer F. Catecholamines in plasma and urine at high altitude. J Appl Physiol 1965;20:607-10.

19 Sawhney RC, Malhotra AS, Singh T. Glucoregulatory hormones in man at high altitude. Eur J Appl Physiol Occup Physiol 1991;62:286-91.

20 Juniper EF, Kline PA, Vanzieleghem MA, et al. Effect of long-term treatment with an inhaled corticosteroid (budesonide) on airway hyperresponsiveness and clinical asthma in nonsteroid-dependent asthmatics. Am Rev Respir Dis 1990;142:832-6.
21 Knox AJ, Campos-Gongora H, Wisniewski A, et al. Modification of bronchial reactivity by physiological concentrations of plasma epinephrine. J Appl Physiol 1992:73:1004-7.

22 Freezer NJ, Croasdell H, Doull IJ, et al. Effect of regular inhaled beclomethasone on exercise and methacholine airway responses in school children with recurrent wheeze. Eur Respir J 1995;8:1488-93.

23 Bergeron MF, Bahr R, Bärtsch P, et al. International Olympic Committee consensus statement on thermoregulatory and altitude challenges for high-level athletes. Br J Sports Med 2012;46:770-9.

24 Fitch KD. An overview of asthma and airway hyper-responsiveness in Olympic athletes. Br J Sports Med 2012;46:413-16.

25 Karjalainen EM, Laitinen A, Sue-Chu M, et al. Evidence of airway inflammation and remodeling in ski athletes with and without bronchial hyperresponsiveness to methacholine. Am J Respir Crit Care Med 2000;161:2086-91.

26 Bougault V, Turmel J, St-Laurent J, et al. Asthma, airway inflammation and epithelial damage in swimmers and cold-air athletes. Eur Respir J 2009:33:740-6.

27 Jones CE, Chan K. Interleukin-17 stimulates the expression of interleukin-8, growth-related oncogene-alpha, and granulocyte-colony-stimulating factor by human airway epithelial cells. Am J Respir Cell Mol Biol 2002;26:748-53.

28 Tan H-L, Regamey N, Brown S, et al. The Th17 pathway in cystic fibrosis lung disease. Am J Respir Crit Care Med 2011:184:252-8.

29 Brodlie M, McKean MC, Johnson GE, et al. Raised interleukin-17 is immunolocalised to neutrophils in cystic fibrosis lung disease. Eur Respir J 2011:37:1378-85

30 Shweiki D, Itin A, Soffer D, et al. Vascular endothelial growth factor induced by hypoxia may mediate hypoxia-initiated angiogenesis. Nature 1992;359:843-5

31 Christoffersson G, Vågesjö E, Vandooren J, et al. VEGF-A recruits a proangiogenic MMP-9-delivering neutrophil subset that induces angiogenesis in transplanted hypoxic tissue. Blood 2012;120:4653-62.

32 Bobic S, Seys S, De Vooght V, et al. Placental growth factor contributes to bronchial neutrophilic inflammation and edema in allergic asthma. Am J Respir Cell Mol Biol 2012;46:781-9

33 Burtscher M, Flatz M, Faulhaber M. Prediction of susceptibility to acute mountain sickness by $\mathrm{SaO}_{2}$ values during short-term exposure to hypoxia. High Alt Med Biol 2004:5:335-40.

34 Karinen HM, Peltonen JE, Kähönen $\mathrm{M}$, et al. Prediction of acute mountain sickness by monitoring arterial oxygen saturation during ascent. High Alt Med Biol 2010;11:325-32

35 Imray C, Wright A, Subudhi A, et al. Acute mountain sickness: pathophysiology, prevention, and treatment. Prog Cardiovasc Dis 2010:52:467-84. 